\title{
Image-design discourses of identity as unique resources of the quality of environment and means of increasing investment attractiveness of the city
}

\author{
Olga Zhelezniak ${ }^{1}$, and Mirya Korelina ${ }^{1, *}$ \\ ${ }^{1}$ Irkutsk National Research Technical University, 664074, Lermontova str, 83, Irkutsk, Russia
}

\begin{abstract}
The paper is devoted to the study of urban identity and imagedesign as unique resources of the quality of environment, and actual means of increasing competitive advantages of the city and its investment attractiveness. The work includes identification of criteria of the qualities of environment, and peculiarities of the Russian comfort urban environment programs, analysis of specifics of regional identity and possibilities of design in the formation of creative authentic environment of the cities, as well as elaboration of the initiative projects for the city, regional images and codes of environment, forms of urban development and the author design. The project works of the "Irkutsk trade axis" / "Irkutsk quarters" not only create comfortable environment but suggest a concept of transformation of these territories into investment attractive "places", combining possible commercial profit with the needs of the city and tasks of the modern life in the unique milieu of the historical city.
\end{abstract}

Paradoxically, in the beginning of the $21^{\text {st }}$ century globalization of the world opens up "the values of cultural diversity as a specific "resource"" [1, P. 50], that transform identity and values of different cultures into the key factor of increasing competitiveness of the city and its investment attractiveness, making them specific tools to work with the future. Respectively, formation of qualitative urban environment, identical and unique, today is the priority task of development of the Russian cities as a part of the state programs. Imagedesign plays a significant role in the creation of authentic milieu and positive image of the city. All these factors determine relevance and novelty of the presented paper, the main purpose of which is to identify peculiarities of regional identity and possibilities of the imagedesign in the formation of individual, artistically valuable and comfortable environment of the Siberian city (on the example of the city of Irkutsk), and also as a means of increasing competitive advantages of the city, inter alia through creation of initiative, experimental and creative projects for the city. Selection of territories of the "Irkutsk trade axis" / "Irkutsk quarters" for the project works, representing the most prospective, debated and significant platforms for the development of Irkutsk, provides the research with additional actuality.

\footnotetext{
* Corresponding author: miria84@mail.ru
} 


\section{From investment to image-design: Theoretical suppositions}

\subsection{Investments. The quality of environment. The Russian programs for development of the comfortable urban environment}

Investment attractiveness as a set of prerequisites determining the relevance of investments is revealed on the basis of a complex of factors. The universal set of criteria for determination of the investment attractiveness includes, inter alia, availability of natural resources, conditions of natural environment, development of culture, etc. [2, 3, 4]. Assessment of the city attractiveness is also possible with the use of foresight technique [5]. In the framework of this method, the indicators of the status of the city are outlined, and among them, the significant place is delegated to the urban milieu, culture, values and spirituality. Along with it, when defining the factors of the investment attractiveness it is necessary to identify competitiveness as the important characteristics of the city. Creation of the positive image of the city contributes to the formation of competitive attractiveness of "the place" $[6,7,8]$. Therefore, today, the indicators of quality and comfortability of the environment and positive reputation of the places are more and more often included into a range of factors characterizing competitiveness of the territory and its attractiveness for investments.

Different treatments of the term "comfortability" are presented in the works of B. I. Kochurov (formulation of criteria for assessment of the quality of life) [9]; Yu. N. Merinov (definition of the environmental and social characteristics of comfortability of the urban milieu) [10], T. A. Dolgacheva (the study of natural environment and its comfortability) [11]; V. B. Kalmanova and A. B. Sukhoveeva (systematization of indicators of quality of the urban environment) [12] et al. Representing quality of the urban environment as a factor of sustainable development, I.N. Ilina points out the significance of preservation of the unique "face" of the city, the presence of the "center" and "ceremonial" quality of the environment [13]. N. N. Ivanova makes accents on the improving image of the city mentioning that the accomplishment is more important for the youth by $15 \%$ but introduction of modern design is a priority for $53 \%$ [14].

The need of increasing quality of the urban environment in Russia is regulated by a number of the state programs. On them, a special role is performed by the priority project "Formation of the comfortable city environment", in the framework of which "the index of the quality of the urban environment" is being developed. The presence of identity of the city, accomplishment of the "symbolic urban sites", and filling the environment with events, etc. are among the key parameters. Another document that allows accelerating the process of design, diminishing city expenses for creation of qualitative milieu and attracting investments are the single standards for accomplishments of the Russian cities.

\subsection{Identity: Siberian specifics. Image-design and creative city}

Today, discourses of the city identity, their modern interpretation and specifics of manifestation and preservation, in many respects are defined by the processes of strengthening "cross-territorial" interactions; destruction of the autochthonous ideals, increasing mobility of residents and development of trans-cultural space that lead to the actualization of local cultures and formation of lifestyles, creolization, hybridity and homogenization of cultures [15].

In this context, the study of the Siberian identity allows identifying the specific "natureconformity" that is treated as an advantage of life in Siberia, "a contribution to the formation of the Siberian identity". Herewith, the connection of "the place" with the value of "own land" is considered. Culture as a component of identity is defined through the dichotomy of "traditional - contemporary". The tolerance of people with their "habit of diversity" of 
environment and ways of life, as well as some "spatial prerequisites" are revealed, which is specifically important when turning to the issues of the identity of the city. At the same time, personal mobility, as the component of the Siberian identity, providing with authentic selfawareness in the dichotomy "we - they» [16], generates outflow of the population, and loss of "the human capital". Appealing to the future of Siberia, the tasks is "to provide the region with a favorable image for life and increasing competition", that is to make the life in the region more comfortable and cheaper [17]. Herewith, "its own form of creativity that is unique can be found for every city" [18, P. 46]. Creativity becomes the part of the city and the means of manifestation of the individuality of the place and formation of the design-code.

The concept of the design-code that is fashionable today and to which refer practically all works about the urban environment is not just the united system of regulation of the accomplishment, but the holistic system of the image-design, embodying eidos of "the place", its identity that naturally unites specifics of the contemporary life of "the place" with traditions and cultural resources of the territory. Identification of the eidos of the place and creation of the peculiar "channels of memory" are the important tasks of the image-design for increasing investment attractiveness through the formation of individual competitiveness of the urban environment.

\subsection{The "Irkutsk trade axis" / "Irkutsk quarters"}

The "Irkutsk trade axis" as the actual image platform of the city that possesses a resource of identity and competitive advantage, and that is capable to impact the development of the positive image of the place, has been formed in Irkutsk for three and half centuries. [19]. The "Irkutsk trade axis" (later "Irkutsk quarters") is the project with the task to formulate the concept of development of the Central district of Irkutsk demonstrating the logics of the territorial development. It intends to create the holistic public space that integrates separate segments of the trade axis that will be more beneficial in the commercial respect and increases capitalization of the territory. It will also help the owners of land to define "commercially and publically attractive" functions of the objects and complexes well beforehand. In addition to that, for creation of the qualitative environment of the "Irkutsk quarters", it is planned to develop architectural and art regulations.

In the existing works, the major attention is devoted to the quarters 130, 103 and 109 (LLC "Siberian laboratory of urbanistic". The concept of the accomplishment of Uritskii Street ("Urban plan") does not solve the issue of reconstruction of the degrading environment and creation of the unique environmental complex that has authentic image of "the place" and the specific historical memory code.

\section{The "Irkutsk trade axis" / "Irkutsk quarters": the initiative design projects of the development of the Irkutsk National Research Technological University}

The tasks of the concepts of the "Irkutsk trade axis" / "Irkutsk quarters", that are being developed in the Irkutsk National Research Technological University, is to increase the investment attractiveness of the territory by disclosure historical and cultural and image potential of "the place" and creation of unique authentic milieus and actual forms of their existence. 


\subsection{Jerusalem stairs: modernization of the historical milieu¹.}

In the framework of common conceptual solutions, the project suggests the new program of "life" of the territory that is connected with utilization of the stairs as the important urban historical and cultural and spatial dominant and considers the development of the author design of forms of landscaping, lighting, cascade reservoirs, etc. On the one side of the stairs, there is a reorganization of the segment located in the limits of Bortsob Revolutsii, Griaznov and Podgornaia streets into the image art-space that establishes a unique Square of Arts inside the quarter with the open view to the stairs. On the other side of the stairs, on the slope of a hill, the landscape scenario develops, turning at the basis of the slope into a complicated system of artificial reservoirs, children's playgrounds and zones for extreme sports, which is built around the amphitheater and the stage for public events.

At the same time, the Jerusalem stairs act as a significant compositional and connecting axis. It begins at the from the upper platform, forming a memorial area in front of the Entrance-Jerusalem Temple and the colonnade of the main entrance, organizes the surrounding historical quarters, integrates art-quarter (the space of the historical allusions) with later development and modern recreation, and completes with the cross-roads ensemble as the key space.

\subsection{The complex development of the territory of the central market and surrounding areas ${ }^{2}$}

This concept is devoted to the creation of the new image and new ideology of "life" of the former Sennaia / Arsenalnaia Square. Its complex transformation envisages designing of territories actual for the contemporary existence of the areas of environmental objects and elements of accomplishment, modernization of the existing fragments of environment and filling them with new functions and making attractive in commercial and public respects. The transportation structure of the market is supposed to be changes with amendment of the traffic schemes for transports and pedestrians, building two additional parking lots, transformation of Chekhov Street into the transit street. Public transportation stations are to be integrated into the common stylistics of "the place".

Comfortable and safe pedestrian connections are proposed for creation of modern and qualitatively functioning public center and organic interaction of the renovated facades with the urban context are envisaged. The territory of the market place is conditionally divided into several functional zones.

The underground cross-road from Uritskii Street is integrated with the new underground space in front of the trade complex, which is connected with the underground level of parking lots and the ground floor of the complex. Separate pavilions are moved to the newly formed space forming the developed commercial and recreational zone. The space between the complex and market is transformed into a recreational walking zone, and all shopping functions are transferred to the in-built premises in the façade of the construction, to the marketplace at the end of the market and in the newly created spatial structure. Additional space above and along the market is occupied by commercial premises and workshops with a possibility of creation of co-working centers. In addition to the food court on the upper floor of the trade complex, the functions of public catering will be performed by small summer cafes. Breadboarding is the important part of the project, as the final design project conveys the atmosphere of a special romanticism inherent in the historic city, organically embedding new, modern forms and functions in this environment.

\footnotetext{
${ }^{1}$ The author is T. Pivneva, the supervisors are O.E. Zhelezniak and M.V. Korelina.

${ }^{2}$ The author is A. Grizdeva, the supervisors are O.E. Zhelezniak and M.V. Korelina.
} 
The author's version proposes not only a new concept of organization of comfortable environment, developing underground urbanistics and the system of public areas in the above-ground level, but has expressive images and stylish image-design, corresponding to "the place", which are built on the play of historical romantics and modern subjects, urbanized systems and natural motives that, as a whole, increases competitiveness and investment resource of the territory.

\subsection{Reconstruction of Uritskii Street ${ }^{3}$}

The concept of formation of "Memory Street", returning us to the ideology of the environment approach that was cultivated in the national culture and professional consciousness in the second half of the $20^{\text {th }}$ century, is a continuation of the subject of imagedesign. The project concept, which in many respects is justified by the status of Uritskii Street as a monument of the environmental architecture, is expressed with the metaphor "Memory Street" and is embodied in the conceptual model. Entrance gate, carousel, the area of one unique (old) tree, painting the ends of buildings, etc. create specific "memory channels" and form environment identity codes.

The basis for the project ideology is the understanding of the environment of the historic city as a space for interpretation of eidos of "the place", for a dialogue contact between history and contemporary epoch, adaptation of different forms and norms of development and introduction of innovations into the existing context. Herewith, the project not only visually identifies and reconstructs the historical milieu, but creates unique fragment of the city that is historically and culturally autochthonous and simultaneously lives full modern life.

The implementation of the project allowed reconstructing a number of buildings into their original form; in separate buildings the plasticity of the facades, almost lost in the later layers, has been opened and recreated, and expressive color image of the street is suggested. In addition to that, the facade painting of the buildings' ends has been performed as one of the first super graphics in Irkutsk, which has served as a symbol of Uritskii Street for a long time [20].

The identity of "the place" that appeared as a result of the environmental design, carries unique images reflecting specifics of the street, and corresponding to the new development programs.

\subsection{Reorganization of Proletarskaia Street ${ }^{4}$}

Creation of the concept of development of the fragment of historical part of the city in the framework of the "Trade axis" from Karl Marx Street to the Embankment of the Angara river can be referred as the experience of "the generating identities" that provides for the renovation of historical environment, increasing quality of environment, positive image of the city and the investment potential of the place.

Proletarskaia Street is treated as a kind of a rod, which strung multifunctional neighborhoods, where the new lives that raise the status of the territories, are planned. The ideology of work with historical environment as a complex multidimensional context with different forms of spatial organization and interaction of public and private spaces reflects actual trends and prospects of development of the historical city. The conflict of functional, historical and cultural, and architectural subjects is resolved by partial transfer of modern

${ }^{3}$ Contributors: A. Tsytsarev, Zh. O. Meerovich, I. Mozharova with participation of I. Khomutnikov, M. Parshikova, T. Rodionova, S. Nefedov, S. Demkov et al.

${ }^{4}$ Contributors: E. Antonova, the supervisors are O. E. Zhelezniak and M. V. Korelina. 
infrastructure into the ground. Stratifying the street vertically on two levels, the underground space is given for parking lots, and the ground - to pedestrians and cyclists

The street forms entrances to inter-quarter spaces, turning them into modern urban fabric. Maximum preservation of architectural monuments and "attributing" them with new functions is envisaged (for example, recreational complex on Rabochaia and Nekrasov Streets). Authentic hotel and art and handicraft quarters, art spaces and cultural and entertainment zone oriented on the residents of the city and tourists are formed.

The set of individual equipment and elements of accomplishment, as well as a series of the art objects is proposed for identification of territory and formation of its image and design-code of the environment. It allows completing the concept of development of the spaces "Irkutsk trade axis" / "Irkutsk quarters".

As a whole, the set of ideas about urban identity and design as the unique resources of the quality of urban environment and actual means to increase competitive advantages of the city, allows establishing common theoretical basis for practical works. The design projects on the "Irkutsk trade axis" / "Irkutsk quarters" not only create authentic liveable environment, but propose a concept of transforming these territories into investment attractive "places" combining possible commercial profit with demands of the city, tasks of contemporary existence of the unique environment of the historical city. Creation and manifestation of identities occur through the design of regional images and codes of environment, unique forms of development of the city, the author design when developing comfortable image environments.

\section{References}

1. V. L. Inozemtsev, Macroregion Siberia: Problems and Prospects, 10, 31-50 (2013)

2. A. R. Zyumalina, Young Scientist, 1, 133 (2011)

3. A. E. Saak, O. A. Kolchina, Investment Management of the Municipal Formation, 336 (2010)

4. B. I. Kochurov, M. A. Zhulina, Problems of Regional Ecology, 5, 89 (2004)

5. V. A. Titova, I. A. Khadjaeva, The Science of Man: Humanitarian Research, 1(11), 91 (2013)

6. R. A. Fatkhutdinov, Global Competitiveness, 464 (2009)

7. M. Yu. Porter, Competitive Advantage: Creating and Sustaining Superior Performance, 592 (1998)

8. Yu. N. Merinov, Ecological and Social Comfort of the City Environment of Rostovon-Don, 140 (2001)

9. T. A. Dolgacheva, Assessment of the comfort of living in the city (on the example of Saransk) (2006)

10. V. B. Kalmanova, A. B. Sukhoveeva, Proceedings of the Samara Scientific Center Russian Academy of Sciences, 16, 878 (2014)

11. I. I. Ilina, Property Relations in the Russian Federation, 5(164), 69 (2015)

12. T. N. Ivanova, Concept, 38(164), 62 (2016)

13. Z. Bauman, Individualized Society, 390 (2005)

14. A. A. Anisimova, Siberian Identity, 176 (2012)

15. H. Landry, Creative City, 399 (2011)

16. E. Grigorieva, A. Repina, Baikal Project, 46, 76 (2015)

17. O. E. Zheleznyak, M. G. Meerovich, Baikal Project, 5, 16 (2005)

18. Y. V. Ragulina, A. V. Bogoviz, A. N. Alekseev, Advances in Intelligent Systems and Computing, 622, 568-573 (2018) 